Article

\title{
Ferromagnetic Oxime-Based Manganese(III) Single-Molecule Magnets with Dimethylformamide and Pyridine as Terminal Ligands
}

\author{
Carlos Rojas-Dotti, Nicolás Moliner, Francesc Lloret and José Martínez-Lillo * (1) \\ Instituto de Ciencia Molecular (ICMol), Universitat de València, C/Catedrático José Beltrán 2, 46980 Paterna, \\ Valencia, Spain; carlos.rojas@uv.es (C.R.-D.); fernando.moliner@uv.es (N.M.); francisco.lloret@uv.es (F.L.) \\ * Correspondence: f.jose.martinez@uv.es; Tel.: + 34-963-544-460
}

Received: 1 December 2018; Accepted: 24 December 2018; Published: 31 December 2018

\begin{abstract}
Two new members of the $\left[\mathrm{Mn}_{6}\right]$ family of single-molecule magnets (SMMs) of formulae $\left[\mathrm{Mn}_{6}\left(\mu_{3}-\mathrm{O}\right)_{2}\left(\mathrm{H}_{2} \mathrm{~N}-\mathrm{sao}\right)_{6}(\mathrm{dmf})_{8}\right]\left(\mathrm{ClO}_{4}\right)_{2}(\mathbf{1})$ and $\left[\mathrm{Mn}_{6}\left(\mu_{3}-\mathrm{O}\right)_{2}\left(\mathrm{H}_{2} \mathrm{~N}-\mathrm{sao}\right)_{6}(\mathrm{py})_{6}(\mathrm{EtOH})_{2}\right]\left[\mathrm{ReO}_{4}\right]_{2} \cdot 4 \mathrm{EtOH}$ (2), $\left(\mathrm{dmf}=\mathrm{N}, \mathrm{N}^{\prime}\right.$-dimethylformamide, py = pyridine, $\mathrm{H}_{2} \mathrm{~N}$-saoH $\mathrm{s}_{2}=$ salicylamidoxime $)$ have been synthesized and characterized structurally and magnetically. Both compounds were straightforwardly prepared from the deprotonation of the $\mathrm{H}_{2} \mathrm{~N}-\mathrm{saoH}_{2}$ ligand in the presence of the desired manganese salt and solvent $(\mathrm{dmf}(\mathbf{1})$ vs. py (2)). Compound $\mathbf{1}$ crystallizes in the triclinic system with space group $P \overline{1}$ and 2 crystallizes in the monoclinic system with space group $P 2_{1} / \mathrm{n}$. In the crystal packing of $\mathbf{1}$ and 2, the $\left(\mathrm{ClO}_{4}\right)^{-}(\mathbf{1})$ and $\left[\mathrm{ReO}_{4}\right]^{-}$(2) anions sit between the cationic $\left[\mathrm{Mn}_{6}\right]^{2+}$ units, which are H-bonded to $-\mathrm{NH}_{2}$ groups from the salicylamidoxime ligands. The study of the magnetic properties of $\mathbf{1}$ and $\mathbf{2}$ revealed ferromagnetic coupling between the $\mathrm{Mn}^{\mathrm{III}}$ metal ions and the occurrence of slow relaxation of the magnetization, which is a typical feature of single-molecule magnet behavior. The cationic nature of these $\left[\mathrm{Mn}_{6}\right]^{2+}$ species suggests that they could be used as suitable building blocks for preparing new magnetic materials exhibiting additional functionalities.
\end{abstract}

Keywords: manganese(III); salicylamidoxime; molecular magnetism; single-molecule magnets

\section{Introduction}

Single-molecule magnets (SMMs) have attracted a great deal of attention during the last two decades [1], because of their potential applications in quantum information processing [2], low-temperature cooling [3], and molecular spintronics [4,5]. Most of the reported SMMs are based on paramagnetic 3D metal ions, the $\mathrm{Mn}^{\mathrm{III}}$ ion being one of the more explored in this multidisciplinary research [6].

In this context, the combination of phenolic oximes and $\mathrm{Mn}^{\mathrm{III}}$ has proven to be particularly successful in the preparation of SMMs [7]. Thus, a large family of hexanuclear [ $\mathrm{Mn}^{\mathrm{III}}{ }_{6}$ ] complexes based on salicylaldoxime and salicylamidoxime ligands (Scheme 1), along with their derivatives, has been investigated [8-20]. All the family members display the SMM phenomenon, with remarkably different magnetic behavior, antiferromagnetic or ferromagnetic, that is strongly affected by the structural distortion of the $\mathrm{Mn}-\mathrm{N}-\mathrm{O}-\mathrm{Mn}$ torsion angles. As a result, it established a semi-quantitative magnetostructural correlation that enables the prediction of the magnetic behavior of new $\left[\mathrm{Mn}^{\mathrm{III}}{ }_{6}\right]$ systems [8-20].

A search on the Cambridge Structural Database (CSD) revealed more than 100 hits of discrete [Mn $\left.{ }^{\mathrm{III}}{ }_{6}\right]$ molecules based on salicylaldoxime and salicylamidoxime ligands. However, only six of them were cationic $\left[\mathrm{Mn}_{6}{ }_{6}\right]^{2+}$ systems, the rest being neutral complexes [17-19]. This singular type of SMMs suggests that they could be used as suitable building blocks for preparing new magnetic materials, 
just by replacing the anion by another anionic species exhibiting an additional functionality [17-19]. For that reason, we are motivated to investigate the crystal structure and magnetic properties of cationic $\left[\mathrm{Mn}_{6}{ }_{6}\right]^{2+}$ SMMs.<smiles>NC(=NO)c1ccccc1O</smiles>

Scheme 1. Structure of the salicylamidoxime ligand $\left(\mathrm{H}_{2} \mathrm{~N}-\mathrm{saoH}_{2}\right)$.

Herein we report two novel cationic $\left[\mathrm{Mn}_{6}\right]^{2+}$ complexes with the formulae $\left[\mathrm{Mn}_{6}\left(\mu_{3}-\mathrm{O}\right)_{2}\left(\mathrm{H}_{2} \mathrm{~N}\right.\right.$ sao $\left.)_{6}(\mathrm{dmf})_{8}\right]\left(\mathrm{ClO}_{4}\right)_{2} \quad(\mathbf{1})$ and $\left[\mathrm{Mn}_{6}\left(\mu_{3}-\mathrm{O}\right)_{2}\left(\mathrm{H}_{2} \mathrm{~N}-\mathrm{sao}\right)_{6}(\mathrm{py})_{6}(\mathrm{EtOH})_{2}\right]\left[\mathrm{ReO}_{4}\right]_{2} \cdot 4 \mathrm{EtOH} \quad(2) \quad(\mathrm{dmf}=$ $\mathrm{N}, \mathrm{N}^{\prime}$-dimethylformamide, py = pyridine, $\mathrm{H}_{2} \mathrm{~N}-\mathrm{saoH}_{2}=$ salicylamidoxime), which have been characterized structurally and magnetically. Both 1 and 2 behave as SMMs.

\section{Materials and Methods}

\subsection{Reagents and Instruments}

All manipulations were performed under aerobic conditions, using materials as received (reagent grade). Although no problems were encountered in this work, care should be taken when using the potentially explosive perchlorate anion. The salicylamidoxime ligand was prepared following the synthetic method described in the literature [21].

Elemental analyses $(\mathrm{C}, \mathrm{H}, \mathrm{N})$ were performed with a CE Instruments CHNS 1100 Elemental Analyzer (samples of 25 (1) and $20 \mathrm{mg}$ (2)) by the Central Service for the Support to Experimental Research (SCSIE) at the University of Valencia. Infrared spectra of $\mathbf{1}$ and $\mathbf{2}$ were recorded with a PerkinElmer Spectrum 65 FT-IR spectrometer in the $4000-400 \mathrm{~cm}^{-1}$ region. Variable-temperature, solid-state direct current (DC) magnetic susceptibility data down to $2.0 \mathrm{~K}$ were collected on a Quantum Design MPMS-XL SQUID magnetometer equipped (Quantum Design, Inc., San Diego, CA, USA) with a 7 T DC magnet. The experimental magnetic data were corrected for the diamagnetic contributions of the constituent atoms $\left(-990.3 \times 10^{-6}(\mathbf{1})\right.$ and $\left.-1219.8 \times 10^{-6} \mathrm{emu} \mathrm{mol}^{-1}(\mathbf{2})\right)$ and also for the sample holder $\left(-3.58 \times 10^{-6}\right.$ and $-3.45 \times 10^{-6} \mathrm{emu} \mathrm{g}^{-1}$ for $\mathbf{1}$ and $\mathbf{2}$, respectively).

\subsection{Single-Crystal X-Ray Diffraction}

X-ray diffraction data of single crystals of dimensions $0.26 \times 0.16 \times 0.04(\mathbf{1})$ and $0.39 \times 0.31 \times$ $0.24 \mathrm{~mm}^{3}$ (2) were collected on a Bruker D8 Venture diffractometer with PHOTON II detector and by using monochromatized Mo- $\mathrm{K}_{\alpha}$ radiation $(\lambda=0.71073 \AA)$. Crystal parameters and refinement results for $\mathbf{1}$ and $\mathbf{2}$ are summarized in Table 1.

The structures were solved by standard direct methods and subsequently completed by Fourier recycling by using the SHELXTL software packages. The obtained models were refined with version 2013/4 of SHELXL against $F^{2}$ on all data by full-matrix least squares [22]. In both systems, all non-hydrogen atoms were refined anisotropically, and the hydrogen atoms were set in calculated positions and refined isotropically by using the riding model. The highest difference Fourier map peaks were 2.262 (1) and $1.282 \mathrm{e}^{-3}$ (2), which are located at $0.935 \AA$ of $\mathrm{Cl}(1)$ and at $1.029 \AA$ of $\operatorname{Re}(1)$, respectively. The graphical manipulations were performed with the DIAMOND program [23].

CCDC numbers for 1 and 2 are 1882221 and 1882222, respectively. These data can be obtained free of charge from the Cambridge Crystallographic Data Center on the web (http:/ / www.ccdc.cam. ac.uk/data_request/cif). 
Table 1. Summary of the crystal data and structure refinement for $\mathbf{1}$ and $\mathbf{2}$.

\begin{tabular}{ccc}
\hline Compound & $\mathbf{1}$ & $\mathbf{2}$ \\
\hline CCDC & 1882221 & 1882222 \\
Formula & $\mathrm{C}_{66} \mathrm{H}_{92} \mathrm{O}_{30} \mathrm{~N}_{20} \mathrm{Cl}_{2} \mathrm{Mn}_{6}$ & $\mathrm{C}_{84} \mathrm{H}_{94} \mathrm{O}_{28} \mathrm{~N}_{18} \mathrm{Mn}_{6} \mathrm{Re}_{2}$ \\
$\mathrm{Mr} / \mathrm{g} \cdot \mathrm{mol}^{-1}$ & 2046.13 & 2505.81 \\
Crystal system & triclinic & monoclinic \\
Space group & $P \overline{\mathbf{1}}$ & $P 2_{1} / n$ \\
$a / \AA$ & $12.603(8)$ & $13.446(2)$ \\
$b / \AA$ & $13.256(8)$ & $23.254(4)$ \\
$c / \AA$ & $14.501(9)$ & $16.458(3)$ \\
$\alpha{ }^{\circ}$ & $114.71(2)$ & 90 \\
$\beta /{ }^{\circ}$ & $98.09(2)$ & $105.06(2)$ \\
$\gamma /{ }^{\circ}$ & $100.59(2)$ & 90 \\
$V / \AA^{3}$ & $2098.2(2)$ & $4649.1(1)$ \\
$Z$ & 1 & 2 \\
$D_{\mathrm{c}} / \mathrm{g} \cdot \mathrm{cm}^{-3}$ & 1.619 & 1.675 \\
$\mu\left(\mathrm{MoK}_{\alpha}\right) / \mathrm{mm}^{-1}$ & 1.032 & 3.244 \\
$F(000)$ & 1052 & 2496 \\
$\mathrm{Crystal} \mathrm{size}$ & $0.26 \times 0.16 \times 0.04$ & $0.39 \times 0.31 \times 0.24$ \\
$\mathrm{Goodness-of-fit} \mathrm{on} F^{2}$ & 1.079 & 1.047 \\
$R_{1}[I>2 \sigma(I)]$ & 0.0623 & 0.0537 \\
$w R_{2}[I>2 \sigma(I)]$ & 0.1731 & 0.1596 \\
$\Delta \rho_{\text {max }}$ min $/ \mathrm{e} \AA$ & $1.282,-2.359$
\end{tabular}

\subsection{Preparation of the Compounds}

\subsubsection{Synthesis of $\left[\mathrm{Mn}_{6}\left(\mu_{3}-\mathrm{O}\right)_{2}\left(\mathrm{H}_{2} \mathrm{~N}-\mathrm{sao}\right)_{6}(\mathrm{dmf})_{8}\right]\left(\mathrm{ClO}_{4}\right)_{2}(\mathbf{1})$}

$\mathrm{Mn}\left(\mathrm{ClO}_{4}\right)_{2} \cdot 6 \mathrm{H}_{2} \mathrm{O}(0.249 \mathrm{~g}, 0.688 \mathrm{mmol})$ was dissolved with continuous stirring in $\mathrm{dmf}(10 \mathrm{~mL})$; then, $\mathrm{H}_{2} \mathrm{~N}-\mathrm{saoH}_{2}(0.103 \mathrm{~g}, 0.670 \mathrm{mmol})$ and $\mathrm{NEt}_{3}(0.5 \mathrm{~mL}, 3.6 \mathrm{mmol})$ were added. The resulting dark green mixture was stirred for $1 \mathrm{~h}$, filtered and layered with $\mathrm{Et}_{2} \mathrm{O}(10 \mathrm{~mL})$. Dark green crystals suitable for $X$-ray diffraction were obtained in 4 days. Yield: $80 \%$. Elemental analysis calculated (found) for $\mathrm{C}_{66} \mathrm{H}_{92} \mathrm{O}_{30} \mathrm{~N}_{20} \mathrm{Cl}_{2} \mathrm{Mn}_{6}$ (1): C, 39.1 (39.7); H, 5.2 (5.0); N, 13.8 (13.9)\%. Selected IR data (in $\mathrm{KBr} / \mathrm{cm}^{-1}$ ): 3332 (m), 2925 (w), 1653 (vs), 1610 (vs), 1533 (m), 1438 (m), 1384 (m), 1317 (m), 1253 (m), 1150 (m), $1121(\mathrm{~s}), 1109(\mathrm{~s}), 1022(\mathrm{~m}), 881(\mathrm{~m}), 762(\mathrm{w}), 685(\mathrm{~s}), 649(\mathrm{~m}), 578(\mathrm{w})$.

\subsubsection{Synthesis of $\left[\mathrm{Mn}_{6}\left(\mu_{3}-\mathrm{O}\right)_{2}\left(\mathrm{H}_{2} \mathrm{~N}-\mathrm{sao}\right)_{6}(\mathrm{py})_{6}(\mathrm{EtOH})_{2}\right]\left[\mathrm{ReO}_{4}\right]_{2} \cdot 4 \mathrm{EtOH}(2)$}

$\mathrm{Mn}\left(\mathrm{NO}_{3}\right)_{2} \cdot 4 \mathrm{H}_{2} \mathrm{O}(0.173 \mathrm{~g}, 0.688 \mathrm{mmol})$ was dissolved with continuous stirring in $\mathrm{EtOH}(20 \mathrm{~mL})$, then $\mathrm{H}_{2} \mathrm{~N}-\mathrm{saoH}_{2}(0.103 \mathrm{~g}, 0.670 \mathrm{mmol})$ was added, followed by pyridine $(1 \mathrm{~mL}, 12.4 \mathrm{mmol})$ and $\mathrm{NEt}_{3}$ $(0.1 \mathrm{~mL}, 0.72 \mathrm{mmol}) . \mathrm{Next},\left(\mathrm{NH}_{4}\right)\left[\mathrm{ReO}_{4}\right](0.184 \mathrm{~g}, 0.688 \mathrm{mmol})$ was added to the dark green solution, which was stirred for $1 \mathrm{~h}$. The final dark brown solution was left to evaporate in a fume hood at room temperature. Crystals of 2 were obtained in 3 days and were suitable for $\mathrm{X}$-ray diffraction. Yield: 70\%. Elemental analysis calculated (found) for $\mathrm{C}_{84} \mathrm{H}_{94} \mathrm{O}_{28} \mathrm{~N}_{18} \mathrm{Mn}_{6} \mathrm{Re}_{2}$ (2): $\mathrm{C}, 40.3$ (40.8); H, 3.8 (4.0); N, 10.1 (9.9)\%. Selected IR data (in KBr/cm ${ }^{-1}$ ): 3426 (vs), 3314 (vs), 1614 (vs), 1564 (m), 1529 (s), 1483 (w), 1442 (s), $1384(\mathrm{w}), 1311(\mathrm{w}), 1251(\mathrm{w}), 1147(\mathrm{vw}), 1022(\mathrm{~m}), 910(\mathrm{~s}), 881(\mathrm{~m}), 755(\mathrm{w}), 683(\mathrm{~m}), 642(\mathrm{w}), 580(\mathrm{vw})$.

\section{Results and Discussion}

\subsection{Synthetic Procedure}

By reacting $\mathrm{Mn}\left(\mathrm{ClO}_{4}\right)_{2} \cdot 6 \mathrm{H}_{2} \mathrm{O}(1)$ and $\mathrm{Mn}\left(\mathrm{NO}_{3}\right)_{2} \cdot 4 \mathrm{H}_{2} \mathrm{O}$ (2) with the salicylamidoxime ligand (Scheme 1) in the presence of the coordinating solvent $\mathrm{dmf}(\mathbf{1})$ and py (2), along with $\mathrm{NEt}_{3}(\mathbf{1}$ and $\mathbf{2})$ and $\left[\mathrm{ReO}_{4}\right]^{-}$(2), we obtained dark green crystals of hexametallic $\mathrm{Mn}^{\mathrm{III}}$ complexes of the well-known family of $\left[\mathrm{Mn}_{6}\right]$ systems. Both $\left(\mathrm{ClO}_{4}\right)^{-}$and $\left[\mathrm{ReO}_{4}\right]^{-}$anions were chosen because of their diamagnetic character, and also for giving a suitable solubility to the final compounds. The crystallization techniques 
employed for 1 and 2 were slow diffusion by layering with $\mathrm{Et}_{2} \mathrm{O}(10 \mathrm{~mL})$ and slow evaporation at room temperature of the resulting solutions, respectively. Both compounds were obtained in satisfactory yields.

It is worth noting that both $\mathbf{1}$ and $\mathbf{2}$ are cationic oxime-based $\left[\mathrm{Mn}_{6}\right]^{2+}$ complexes, and only six systems of this type exist in literature, all of them being obtained with the salicylamidoxime ligand [17-19]. This fact is in contrast to the results obtained from analogous reactions employing similar phenolic oximes, such as salicylaldoxime and its alkyl derivatives, where the isolated complex of the reported works is always a neutral $\left[\mathrm{Mn}_{6}\right]$ or $\left[\mathrm{Mn}_{3}\right]$ system.

\subsection{Description of the Crystal Structures}

The crystal structure and exact chemical composition of $\mathbf{1}$ and $\mathbf{2}$ were established by single-crystal $X$-ray diffraction. While 1 crystallizes in the triclinic crystal system with space group $P \overline{1}, 2$ crystallizes in the monoclinic crystal system with space group $P 2_{1} / n$ (Table 1 ). The structures of $\mathbf{1}$ and $\mathbf{2}$ are made up of $\left[\mathrm{Mn}_{6}\right]^{2+}$ cations $(\mathbf{1}$ and 2$)$ and $\left(\mathrm{ClO}_{4}\right)^{-}(\mathbf{1})$ and $\left[\mathrm{ReO}_{4}\right]^{-}(\mathbf{2})$ anions. There are solvent molecules of crystallization in only 2 , these are EtOH molecules.

Each cationic $\left[\mathrm{Mn}_{6}\right]^{2+}$ unit contains two symmetry equivalent $\left\{\mathrm{Mn}_{3}\left(\mu_{3}-\mathrm{O}\right)\right\}$ triangular moieties, which are linked by two phenolate and two oximate $\mathrm{O}$-atoms and related by an inversion center (Figure 1). Each edge of the triangle is spanned by the $-\mathrm{N}-\mathrm{O}-$ group of the salicylamidoxime ligand, with the central oxo ion displaced 0.102 (1) and $0.184 \AA$ (2) above the plane of the $\left[\mathrm{Mn}_{3}\right]$ triangle, towards the $\mathrm{dmf}(\mathbf{1})$ and py (2) terminal ligands.

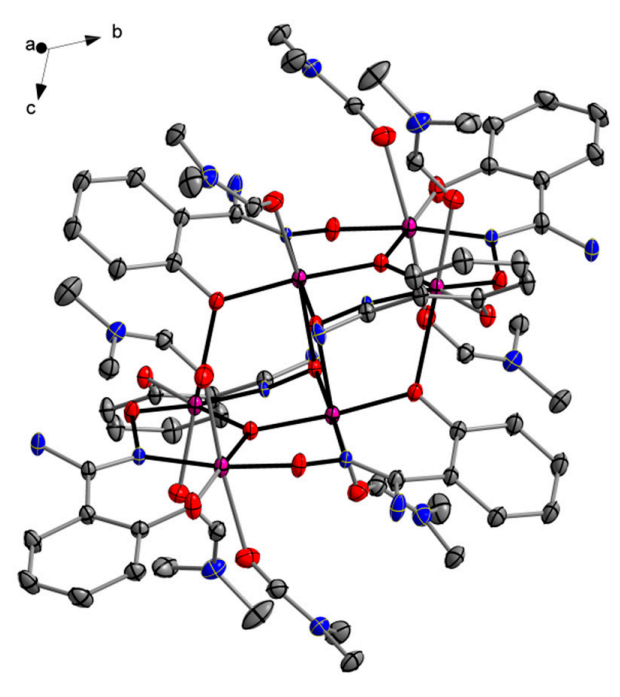

(a)

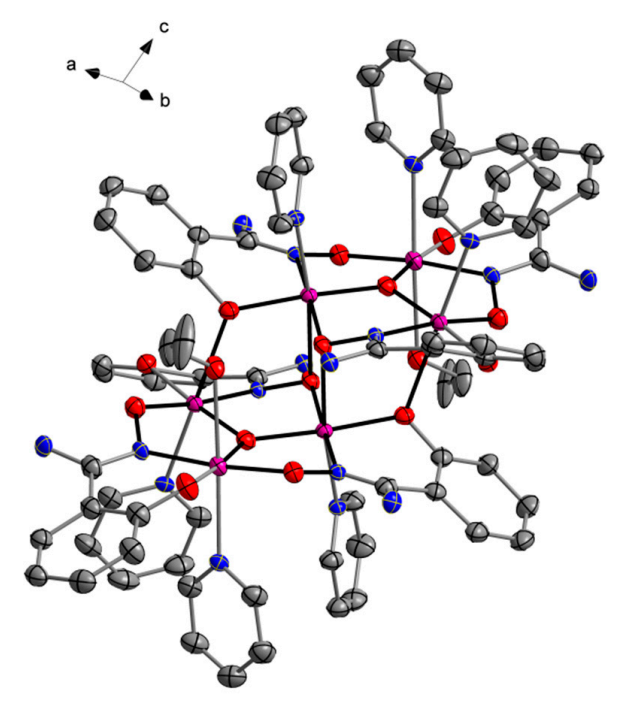

(b)

Figure 1. (a) Molecular structure of the $\left[\mathrm{Mn}_{6}\left(\mu_{3}-\mathrm{O}\right)_{2}\left(\mathrm{H}_{2} \mathrm{~N}-\mathrm{sao}\right)_{6}(\mathrm{dmf})_{8}\right]^{2+}$ cation of $\mathbf{1}$. $\mathrm{H}$ atoms and $\left(\mathrm{ClO}_{4}\right)^{-}$anion have been omitted for clarity. Thermal ellipsoids are depicted at $50 \%$ probability level. (b) Molecular structure of the $\left[\mathrm{Mn}_{6}\left(\mu_{3}-\mathrm{O}\right)_{2}\left(\mathrm{H}_{2} \mathrm{~N}-\mathrm{sao}\right)_{6}(\mathrm{py})_{6}(\mathrm{EtOH})_{2}\right]^{2+}$ cation of 2 . H atoms, $\left[\mathrm{ReO}_{4}\right]^{-}$ anions and $\mathrm{EtOH}$ solvent molecules have been omitted for clarity. Thermal ellipsoids are depicted at $50 \%$ probability level. Color code: Pink, Mn; red, O; blue, N; grey, C.

The six $\mathrm{Mn}^{\mathrm{III}}$ ions in the core of $\mathbf{1}$ and $\mathbf{2}$ exhibit coordination environments rather similar to those of previously reported salicylamidoxime-based $\left[\mathrm{Mn}_{6}\right]^{2+}$ complexes [17-19], with distorted octahedral geometries and Jahn-Teller axes approximately perpendicular to the $\left[\mathrm{Mn}_{3}\right]$ planes. The remaining coordination site on the third $\mathrm{Mn}$ ion $[\mathrm{Mn}(2 \mathrm{a})]((\mathrm{a})=1-\mathrm{x}, 1-\mathrm{y}, 1-\mathrm{z}$ for 1 and $(\mathrm{a})=1-\mathrm{x}, 1-\mathrm{y}$, $-\mathrm{z}$ for 2) is occupied by a dmf (in 1) or EtOH (in 2) molecule. The Mn-N-O-Mn torsion angles of the $\left[\mathrm{Mn}_{3} \mathrm{III}_{3}\left(\mu_{3}-\mathrm{O}\right)-\left(\mathrm{H}_{2} \mathrm{~N}-\mathrm{sao}\right)_{3}\right]$ triangular units are $46.5^{\circ}, 36.3^{\circ}$ and $30.3^{\circ}$ for $\mathbf{1}$ and $41.4^{\circ}, 38.1^{\circ}, 28.9^{\circ}$ for 2 (Table 2). 
Table 2. Selected magneto-structural parameters for compounds $\mathbf{1}$ and $\mathbf{2 .}$

\begin{tabular}{ccccccccc}
\hline \multirow{2}{*}{ Compound } & $\begin{array}{c}\text { Crystal } \\
\text { System }\end{array}$ & $\begin{array}{c}\text { Space } \\
\text { Group }\end{array}$ & $\begin{array}{c}\alpha /^{\circ} \\
(\mathbf{M n}-\mathbf{N}-\mathbf{O}-\mathbf{M n})\end{array}$ & $J_{\mathbf{1}} / \mathbf{c m}^{-\mathbf{1}}$ & $J_{\mathbf{2}} / \mathbf{c m}^{-\mathbf{1}}$ & $g$ & $\boldsymbol{\tau}_{\mathbf{0}} / \mathbf{s}^{-\mathbf{1}}$ & \multirow{2}{*}{$E^{\# / \mathbf{K}}$} \\
\hline $\mathbf{1}$ & triclinic & $P_{\overline{\mathbf{1}}}$ & $46.5,36.3,30.3$ & +0.90 & +0.84 & 1.99 & $1.6 \times 10^{-11}$ & 66 \\
$\mathbf{2}$ & monoclinic & $P 2_{1} / n$ & $41.4,38.1,28.9$ & +1.88 & +0.72 & 1.98 & $8.4 \times 10^{-9}$ & 41 \\
\hline
\end{tabular}

In the crystal packing of $\mathbf{1}$ and $\mathbf{2}$, the $\left(\mathrm{ClO}_{4}\right)^{-}(\mathbf{1})$ and $\left[\mathrm{ReO}_{4}\right]^{-}(\mathbf{2})$ anions sit between the cationic $\left[\mathrm{Mn}_{6}\right]^{2+}$ units, which are $\mathrm{H}$-bonded to $-\mathrm{NH}_{2}$ groups from salicylamidoxime ligands. In 2 the $\mathrm{O} \cdots \mathrm{N}$ distances are shorter than in $\mathbf{1}$, linking the anions and cations into chains $[\mathrm{N}(4) \cdots \mathrm{O}(14 \mathrm{~b})$ distance of 2.895(1) $\AA$; (b) $\left.=\frac{1}{2}-\mathrm{x}, \frac{1}{2}+\mathrm{y}, \frac{1}{2}-\mathrm{z}\right]$, as shown in Figure 2. In 1, the cationic $\left[\mathrm{Mn}_{6}\right]^{2+}$ units are somewhat less separated from each other, the shortest intermolecular Mn $\cdots$ Mn distance being 9.831(1)

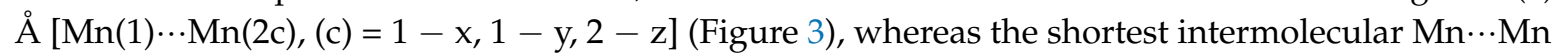
distance in 2 is $10.467(1) \AA\left[\mathrm{Mn}(1) \cdots \mathrm{Mn}(2 \mathrm{~b}),(\mathrm{b})=\frac{1}{2}-\mathrm{x}, \frac{1}{2}+\mathrm{y}, \frac{1}{2}-\mathrm{z}\right]$ (Figure 4).

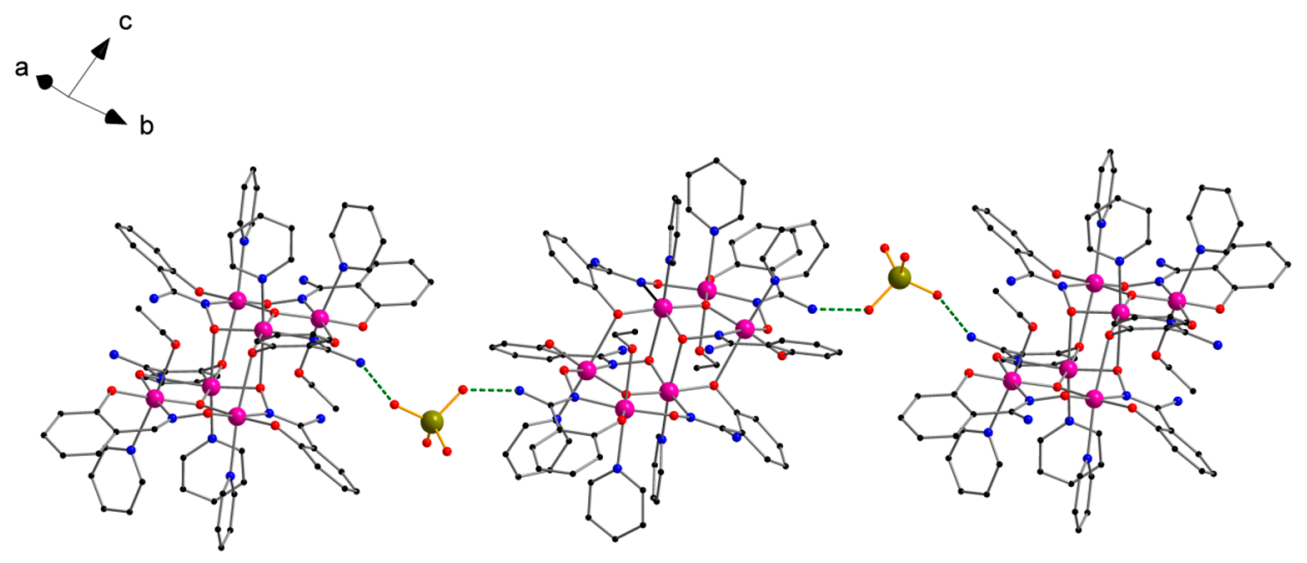

Figure 2. Perspective view of the one-dimensional arrangement of $\left[\mathrm{Mn}_{6}\left(\mu_{3}-\mathrm{O}\right)_{2}\left(\mathrm{H}_{2} \mathrm{~N}-\mathrm{sao}\right)_{6}(\mathrm{py})_{6}(\mathrm{EtOH})_{2}\right]^{2+}$ cations and $\left[\mathrm{ReO}_{4}\right]^{-}$anions in the crystal of compound 2 through $\mathrm{H}$-bonding interactions (dashed lines). $\mathrm{H}$ atoms and solvent molecules have been omitted for clarity. Color code: Pink, Mn; red, O; blue, N; black, C; green, Re.

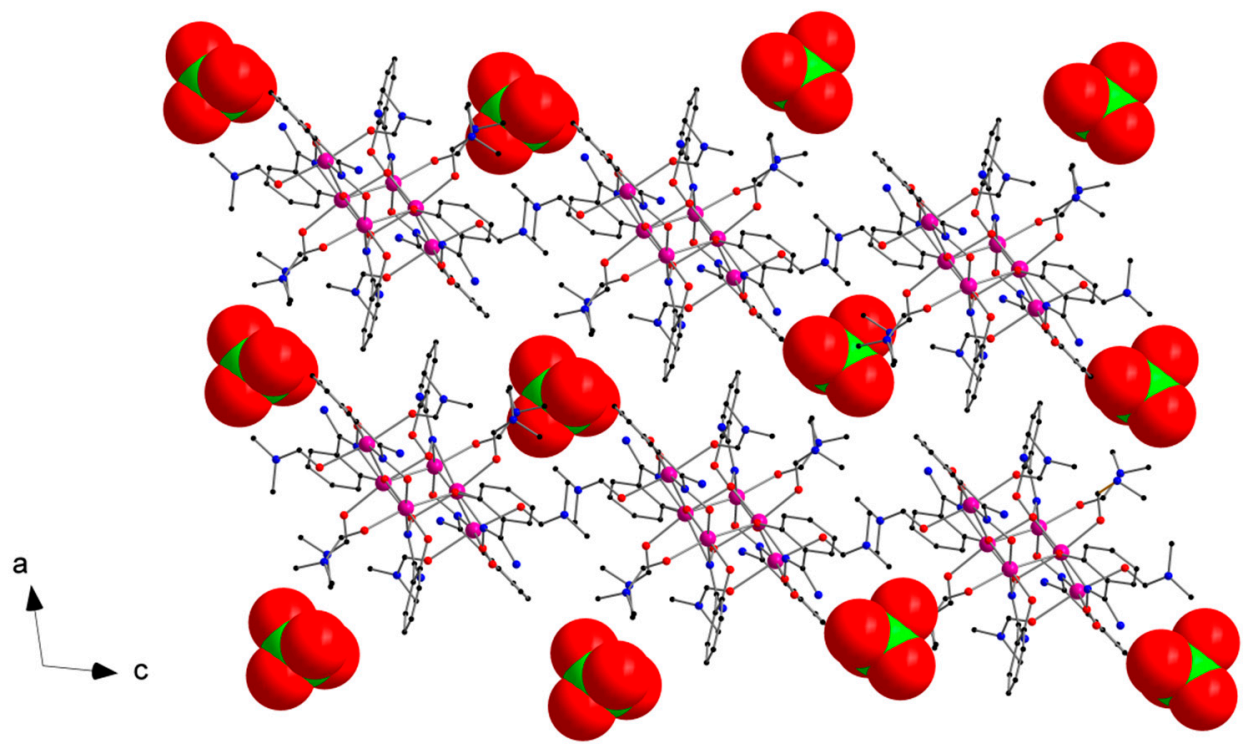

Figure 3. View along the crystallographic $b$ axis of a fragment of the packing of 1 showing the arrangement of the $\left[\mathrm{Mn}_{6}\right]^{2+}$ cations and $\left(\mathrm{ClO}_{4}\right)^{-}$anions (space-filling model). $\mathrm{H}$ atoms have been omitted for clarity. Colour code: Pink, Mn; red, O; blue, N; black, C; green, $\mathrm{Cl}$. 


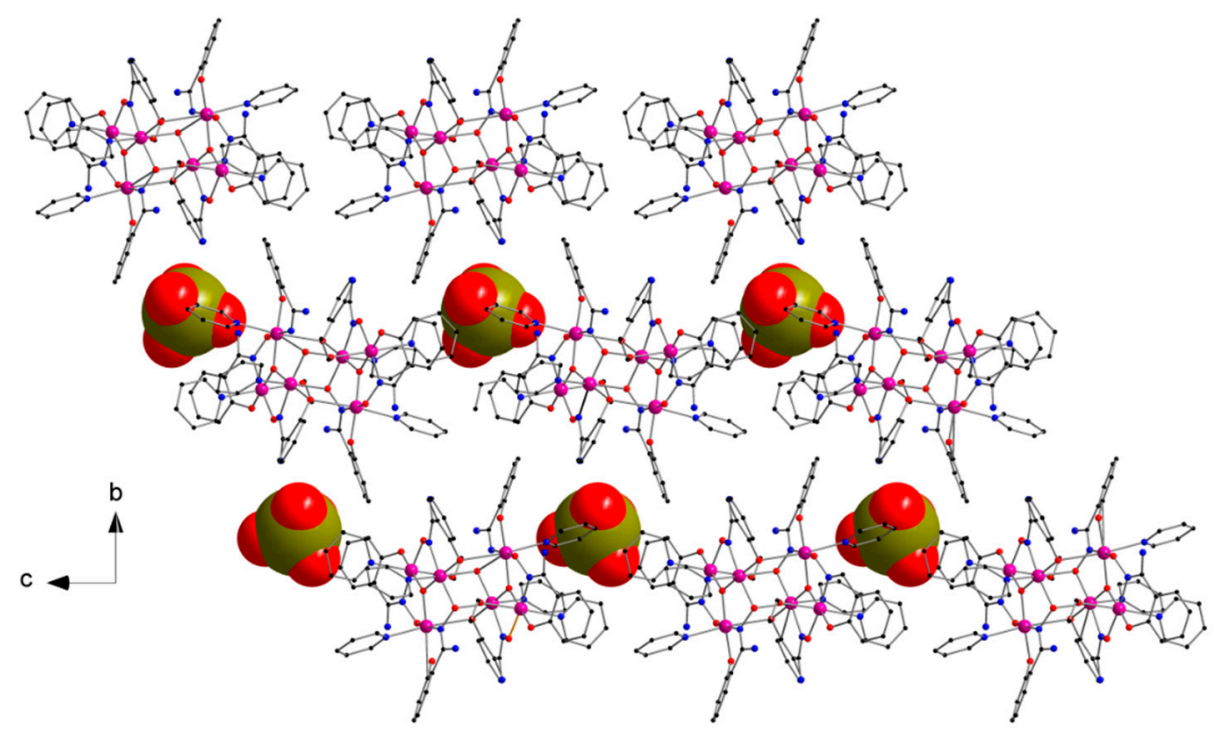

Figure 4. View along the crystallographic $a$ axis of a fragment of the packing of 2 showing the arrangement of the $\left[\mathrm{Mn}_{6}\right]^{2+}$ cations and $\left[\mathrm{ReO}_{4}\right]^{-}$anions (space-filling model). $\mathrm{H}$ atoms have been omitted for clarity. Color code: Pink, Mn; red, O; blue, N; black, C; green, Re.

In both compounds, additional weak C $\cdots C$ interactions of different types are also observed. In 1, there exist $\pi \cdots \pi$ off-center parallel stacking interactions of approximately $3.38 \AA$ between aromatic rings of salicylamidoxime ligands of adjacent $\left[\mathrm{Mn}_{6}\right]^{2+}$ complexes, and also weak $\mathrm{C}-\mathrm{H} \cdots \mathrm{C}(\mathrm{O})$ interactions between $\mathrm{dmf}$ molecules of neighboring $\left[\mathrm{Mn}_{6}\right]^{2+}$ cations (ca. $3.45 \AA$ ). In $2, \pi \cdots \pi$ edge-to-face stacking interactions of ca. $3.49 \AA$ A connect aromatic rings of coordinated py molecules and salicylamidoxime ligands of adjacent $\left[\mathrm{Mn}_{6}\right]^{2+}$ units. All these additional interactions help in stabilizing the supramolecular arrangement in $\mathbf{1}$ and $\mathbf{2}$.

\subsection{Magnetic Properties}

DC magnetic susceptibility measurements were performed on microcrystalline samples of $\mathbf{1}$ and 2 in the 2.0-300 K temperature range and under an external magnetic field of $0.1 \mathrm{~T}$. The magnetic properties of 1 and 2 in the form of $\chi_{\mathrm{M}} T$ vs. $T$ plot ( $\chi_{\mathrm{M}}$ being the molar magnetic susceptibility), are shown in Figure 5. The $\chi_{\mathrm{M}} T$ values observed at $300 \mathrm{~K}$ are approximately 20.2 and $20.7 \mathrm{~cm}^{3} \cdot \mathrm{mol}^{-1}$ $\mathrm{K}$ for $\mathbf{1}$ and 2, respectively. Although these values are somewhat higher than that expected for six magnetically isolated $\mathrm{Mn}{ }^{\mathrm{III}}$ ions $\left(\chi_{\mathrm{M}} T \approx 18.0 \mathrm{~cm}^{3} \cdot \mathrm{mol}^{-1} \mathrm{~K}\right.$ with $\left.g=1.99\right)$, they have been previously observed in ferromagnetically coupled [ $\left.\mathrm{Mn}_{6}\right]$ systems [8-20]. Upon cooling, the $\chi_{\mathrm{M}} T$ values rise gradually with decreasing temperature for both compounds, reaching maxima of $38.9 \mathrm{~cm}^{3} \mathrm{~mol}^{-1} \mathrm{~K}$ at $8.0 \mathrm{~K}$ for 1 and $35.8 \mathrm{~cm}^{3} \cdot \mathrm{mol}^{-1} \mathrm{~K}$ at $17.0 \mathrm{~K}$ for 2 . In both compounds, $\chi_{\mathrm{M}} T$ values decrease at lower temperatures giving final values of $23.0(\mathbf{1})$ and $13.0 \mathrm{~cm}^{3} \cdot \mathrm{mol}^{-1} \mathrm{~K}(\mathbf{2})$ at $2.0 \mathrm{~K}$, which are observed due to the presence of intermolecular interactions and/or zero-field splitting (ZFS) effects.

The experimental data of the $\chi_{\mathrm{M}} T$ vs. $T$ plots of 1 and 2 were treated by using the $2 J$ model described by the Hamiltonian of Equation (1), where $J_{1}$ and $J_{2}$ are the exchange coupling constants for the intramolecular $\mathrm{Mn}-\mathrm{Mn}$ interactions associated with exchange pathways involving the $\mathrm{Mn}-\mathrm{N}-\mathrm{O}-\mathrm{Mn}$ torsion angles of the $\left[\mathrm{Mn}_{6}\right]$ core, and $g$ is the Lande factor for the $\mathrm{Mn}^{\mathrm{III}}$ ions. The theoretical parameters thus obtained are summarized in Table 2.

$$
\begin{aligned}
& \hat{H}=-2 J_{1}\left(\hat{S}_{1} \hat{S}_{3}+\hat{S}_{1} \hat{S}_{3 \prime}+\hat{S}_{1} \hat{S}_{1 \prime}+\hat{S}_{1,} \hat{S}_{3}+\hat{S}_{1,} \hat{S}_{3 \prime}\right) \\
& -2 J_{2}\left(\hat{S}_{1} \hat{S}_{2}+\hat{S}_{2} \hat{S}_{3}+\hat{S}_{1,} \hat{S}_{2 \prime}+\hat{S}_{2 \prime} \hat{S}_{3 \prime}\right)+\mu_{B} g H \hat{S}
\end{aligned}
$$


These features reveal an intramolecular ferromagnetic coupling between the $\mathrm{Mn}^{\mathrm{III}}$ metal ions in both 1 and 2. In previous studies dealing with DFT calculations on salicylamidoxime-based [ $\left.\mathrm{Mn}_{6}\right]$ complexes [16], a critical angle (ca. $27.0^{\circ}$ ) that is directly correlated to the $\mathrm{Mn}-\mathrm{N}-\mathrm{O}-\mathrm{Mn}$ exchange pathway between neighboring $\mathrm{Mn}^{\mathrm{III}}$ ions was found. $\mathrm{Mn}-\mathrm{N}-\mathrm{O}-\mathrm{Mn}$ torsion angles upper than this critical angle switch the magnetic exchange from antiferromagnetic $(J<0)$ to ferromagnetic $(J>0)$. Given that $\mathbf{1}$ and $\mathbf{2}$ show $\mathrm{Mn}-\mathrm{N}-\mathrm{O}-\mathrm{Mn}$ torsion angles higher than $27.0^{\circ}$, it would be expected to obtain a ferromagnetic coupling as the predominant magnetic interaction for both compounds, as observed experimentally (Figure 5 and Table 2).

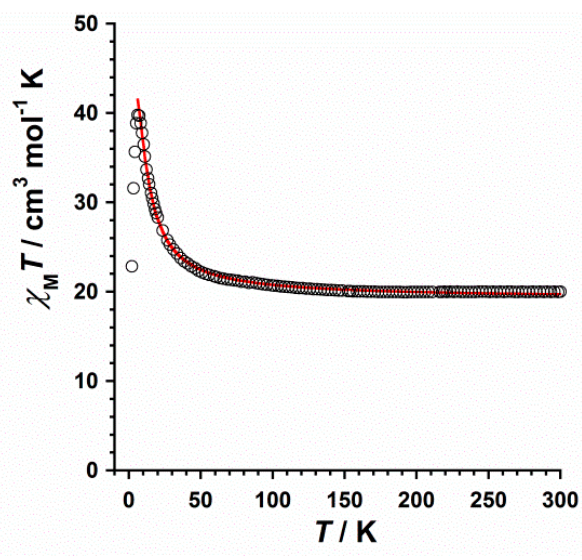

(a)

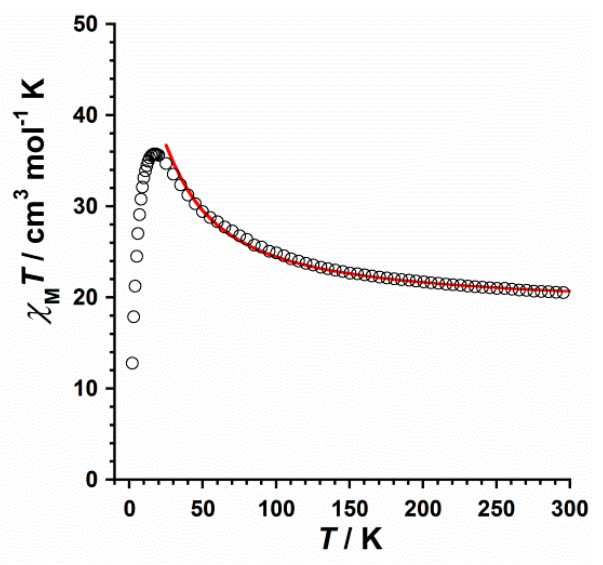

(b)

Figure 5. Thermal variation of the $\chi_{M} T$ product for compounds $1(\mathbf{a})$ and $\mathbf{2}(\mathbf{b})$. The solid red line represents the best-fit of the experimental data.

The complexes that form the large family of oxime-based $\left[\mathrm{Mn}^{\mathrm{III}}{ }_{6}\right] \mathrm{SMMs}$ display ground state spin values that vary from 4 to 12 . In general, a spin value of $S=4$ is found in antiferromagnetic [ $\mathrm{Mn}^{\mathrm{III}}{ }_{6}$ ] systems, whereas ferromagnetic [ $\mathrm{Mn}^{\mathrm{III}}{ }_{6}$ ] complexes show a spin value of $\mathrm{S}=12$. A ground state spin value of $S=12$ was obtained for $\mathbf{1}$ and $\mathbf{2}$ from the magnetic susceptibility data, hence supporting the ferromagnetic nature for both compounds. Thus, the isotropic simulation of the magnetic susceptibility of $\mathbf{1}$ and $\mathbf{2}$ generated the plots of the energy versus total spin shown in Figure 6. The first excited state found in $\mathbf{1}$ is $\mathrm{S}=11$ placed at $2.25 \mathrm{~cm}^{-1}$, and the first excited state in $\mathbf{2}$ is also $\mathrm{S}=11$, which is located at $1.85 \mathrm{~cm}^{-1}$ (Figure 6).

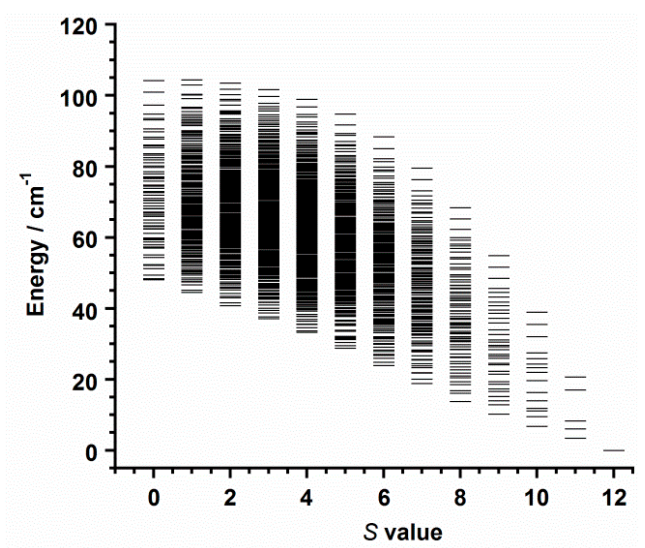

(a)

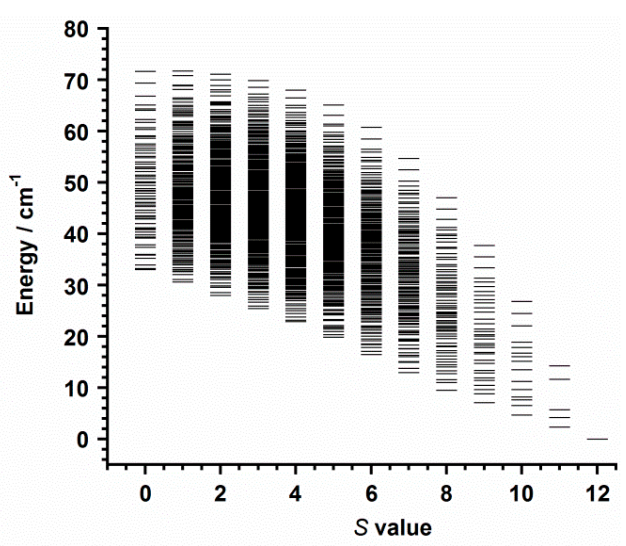

(b)

Figure 6. Plot of energy versus total spin state, extracted from the isotropic simulation of the susceptibility data for $\mathbf{1}$ (a) and $\mathbf{2}$ (b). 
Additionally, variable temperature-variable field DC magnetization data were measured for 1 and 2 in the 2-7 K temperature and 0.5-7.0 $\mathrm{T}$ field ranges. The experimental data are given as reduced magnetization $\left(M / N \mu_{B}\right.$ versus $\left.\mu_{0} H / T\right)$ in Figure 7 , which were fitted to a Zeeman plus axial zero-field splitting Hamiltonian $\left(\hat{H}=D\left(\hat{\mathrm{S}}_{\mathrm{z}}{ }^{2}-\mathrm{S}(\mathrm{S}+1) / 3\right)+\mu_{B} g H \hat{\mathrm{S}}\right.$, where $D$ is the axial anisotropy of the cationic $\left[\mathrm{Mn}_{6}\right]^{2+}$ complex, $\mu_{B}$ is the Bohr magneton, $\hat{\mathrm{S}}_{\mathrm{z}}$ is the easy-axis spin operator, and $H$ is the applied field) assuming only the ground state is populated. The best fits afforded the parameters $S=12, g=1.99$ and $D=-0.48 \mathrm{~cm}^{-1}$ for 1 and $\mathrm{S}=12, g=1.98$ and $D=-0.39 \mathrm{~cm}^{-1}$ for 2 , which are in line with those values reported for similar cationic $\left[\mathrm{Mn}_{6}\right]^{2+}$ complexes [17-19].

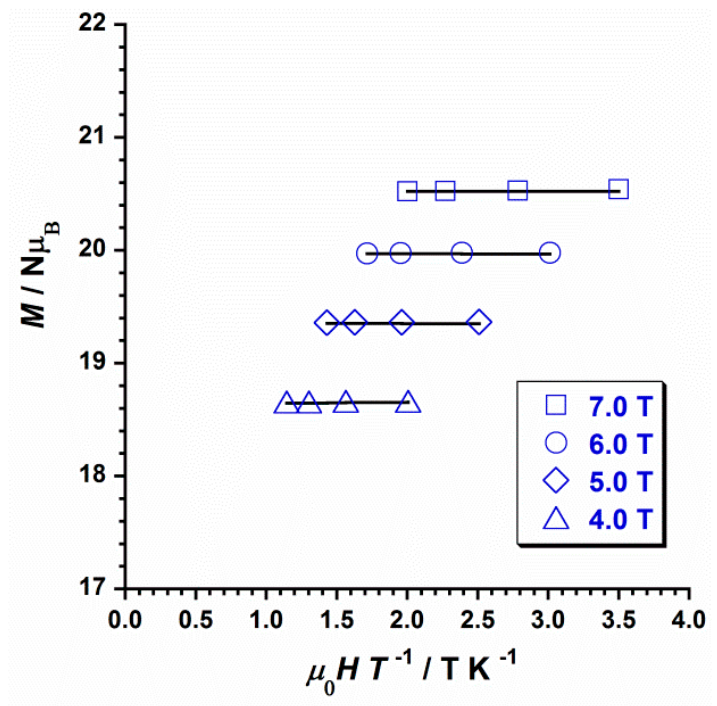

(a)

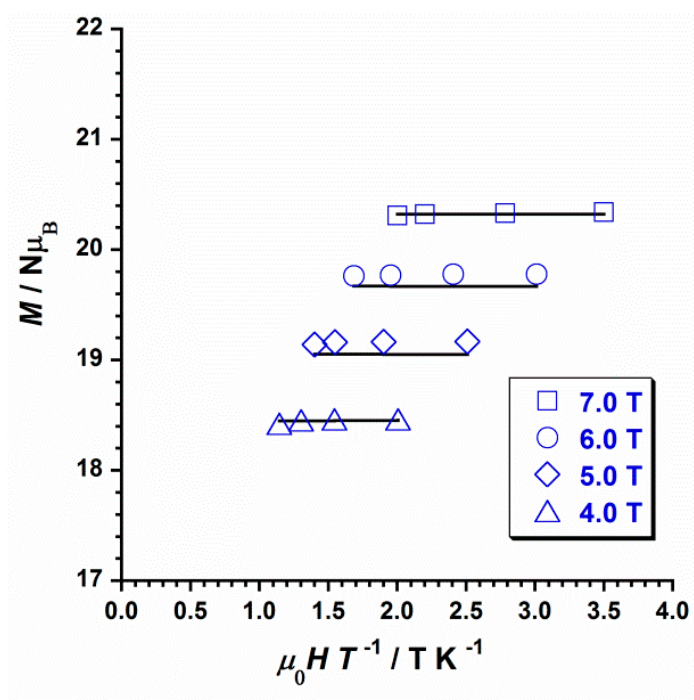

(b)

Figure 7. Plot of the reduced magnetization $\left(M / N \mu_{B}\right.$ versus $\left.\mu_{0} H / T\right)$ for $\mathbf{1}(\mathbf{a})$ and $\mathbf{2}(\mathbf{b})$ at 4, 5, 6 and $7 \mathrm{~T}$ fields and temperatures $2-5 \mathrm{~K}$. The solid lines represent the best fit of the experimental data.

AC susceptibility measurements were performed on samples of $\mathbf{1}$ and $\mathbf{2}$ in the temperature range $2-10 \mathrm{~K}$, in zero applied DC field, and a $3.9 \mathrm{G}$ AC field oscillating in the $5-1000 \mathrm{~Hz}$ range of frequencies. Out-of-phase AC signals $\left(\chi_{M}^{\prime \prime}\right)$ for $\mathbf{1}$ and $\mathbf{2}$ are shown in Figure 8. The respective $\chi^{\prime \prime}{ }_{M}$ versus $T$ plots exhibited frequency dependence of the $\chi^{\prime \prime}{ }_{M}$ maxima for $\mathbf{1}$ and $\mathbf{2}$. This feature is consistent with SMM behavior. In addition, it was observed that the $\chi^{\prime \prime}{ }_{\mathrm{M}}$ maxima increased with the decreasing frequency for both compounds. These data were fitted to the Arrhenius equation $\left(\tau=\tau_{\mathrm{o}} \exp \left(E^{\#} / k_{\mathrm{B}} T\right)\right.$, where $\tau_{\mathrm{o}}$ is the pre-exponential factor, $\tau$ is the relaxation time, $E^{\#}$ is the barrier to relaxation of the magnetization, and $k_{\mathrm{B}}$ is the Boltzmann constant) and plotted in the respective insets of Figure 8 . The values obtained for the $\tau_{\mathrm{o}}$ and $E^{\#}$ parameters are listed in Table 2. The $E^{\#}$ values for $\mathbf{1}\left[66.0 \mathrm{~K}\left(45.9 \mathrm{~cm}^{-1}\right)\right]$ and $2\left[41.0 \mathrm{~K}\left(28.5 \mathrm{~cm}^{-1}\right)\right]$ fall into the range for previously reported salicylamidoxime-based [ $\mathrm{Mn}_{6}^{\text {III }}$ ] complexes $\left(24.0 \mathrm{~K}\left(16.7 \mathrm{~cm}^{-1}\right)<E^{\#}<86.0 \mathrm{~K}\left(59.8 \mathrm{~cm}^{-1}\right)\right)$. Nevertheless, it is worth pointing out that the $E^{\#}$ value calculated for $\mathbf{1}$ is the higher obtained so far for a cationic oxime-based $\left[\mathrm{Mn}^{\mathrm{III}}{ }_{6}\right]^{2+}$ single-molecule magnet.

This last result is interesting since this type of cationic SMMs can be used as precursors of new multifunctional magnetic materials because the $\left(\mathrm{ClO}_{4}\right)^{-}(\mathbf{1})$ and $\left[\mathrm{ReO}_{4}\right]^{-}(2)$ anions can be changed through the incorporation of anionic species that bring another physical property or functionality to the final material, for instance, conductivity or luminescence. 


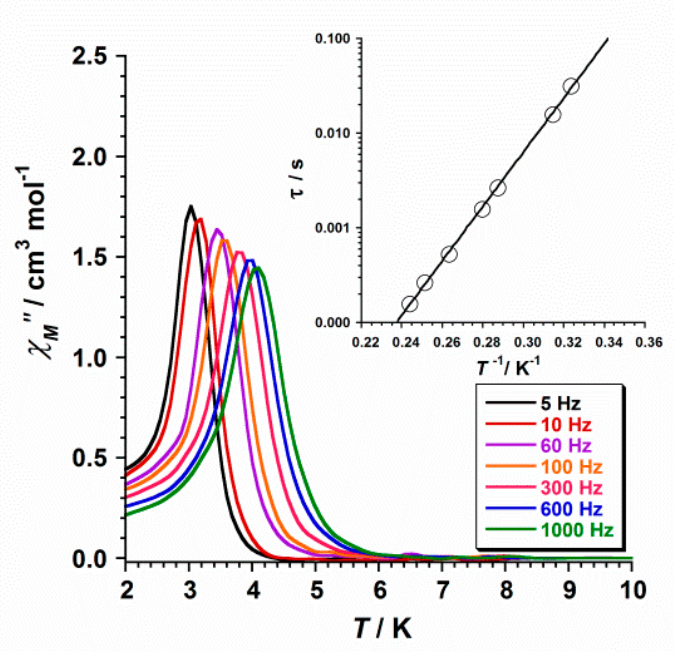

(a)

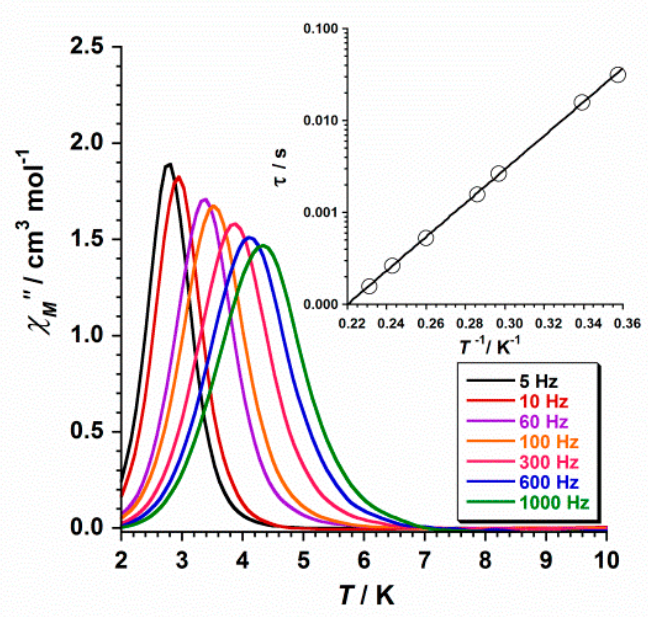

(b)

Figure 8. Out-of-phase AC susceptibility ( $\left.\chi^{\prime \prime} M\right)$ versus $T$ plots for compounds $\mathbf{1}(\mathbf{a})$ and $\mathbf{2}(\mathbf{b})$. The insets show the Arrhenius best-fit plot (see text).

\section{Conclusions}

In summary, two new members of the family of oxime-based $\left[\mathrm{Mn}_{6}\right]$ complexes have been synthesized and magnetostructurally characterized. Both compounds display a magnetic behavior consistent with the single-molecule magnet (SMM) phenomenon. The barrier value to the relaxation of the magnetization $\left(E^{\#}\right)$ for compound $\mathbf{1}$ is the highest reported so far for cationic oxime-based $\left[\mathrm{Mn}_{6}\right]^{2+}$ systems. Finally, due to their cationic character, these singular SMMs could be used as suitable building blocks for preparing new magnetic materials, just by replacing the anion by another anionic species exhibiting an additional functionality, namely, conductivity or luminescence. This work is in progress.

Author Contributions: J.M.-L. and F.L. obtained funding for the project. C.R.-D. performed the synthesis and the X-ray data collection. N.M. designed and carried out the SQUID measurements. J.M.-L. analyzed the data associated with all the experiments and wrote the manuscript, which all authors discussed and commented on.

Funding: This research was funded by the Spanish Ministry of Science, Innovation and Universities with grant numbers MDM-2015-0538 and CTQ2016-75068P.

Acknowledgments: The Spanish “Ramón y Cajal” Programme is gratefully acknowledged.

Conflicts of Interest: The authors declare no conflict of interest.

\section{References}

1. Sessoli, R.; Gatteschi, D. Quantum Tunneling of Magnetization and Related Phenomena in Molecular Materials. Angew. Chem. Int. Ed. 2003, 42, 268-297. [CrossRef]

2. Timco, G.A.; McInnes, E.J.L.; Winpenny, R.E.P. Physical studies of heterometallic rings: An ideal system for studying magnetically-coupled systems. Chem. Soc. Rev. 2013, 42, 1796-1806. [CrossRef] [PubMed]

3. Evangelisti, M.; Brechin, E.K. Recipes for enhanced molecular cooling. Dalton Trans. 2010, 39, 4672-4676. [CrossRef] [PubMed]

4. Bogani, L.; Wernsdorfer, W. Molecular spintronics using single-molecule magnets. Nat. Mater. 2008, 7 , 179-186. [CrossRef] [PubMed]

5. Tyagi, P.; Li, D.; Holmes, S.M.; Hinds, B.J. Molecular Electrodes at the Exposed Edge of Metal/Insulator/ Metal Trilayer Structures. J. Am. Chem. Soc. 2007, 129, 4929-4938. [CrossRef]

6. Ferrando-Soria, J.; Vallejo, J.; Castellano, M.; Martínez-Lillo, J.; Pardo, E.; Cano, J.; Castro, I.; Lloret, F.; Ruiz-García, R.; Julve, M. Molecular magnetism, quo vadis? A historical perspective from a coordination chemist viewpoint. Coord. Chem. Rev. 2017, 339, 17-103. [CrossRef] 
7. Milios, C.J.; Raptopoulou, C.P.; Terzis, A.; Lloret, F.; Vicente, R.; Perlepes, S.P.; Escuer, A. Hexanuclear manganese(III) single-molecule magnets. Angew. Chem. Int. Ed. 2004, 43, 210-212. [CrossRef]

8. Milios, C.J.; Vinslava, A.; Wood, P.A.; Parsons, S.; Wernsdorfer, W.; Christou, G.; Perlepes, S.P.; Brechin, E.K. A Single-Molecule Magnet with a "Twist". J. Am. Chem. Soc. 2007, 129, 8-9. [CrossRef]

9. Milios, C.J.; Vinslava, A.; Wernsdorfer, W.; Moggach, S.; Parsons, S.; Perlepes, S.P.; Christou, G.; Brechin, E.K. A Record Anisotropy Barrier for a Single-Molecule Magnet. J. Am. Chem. Soc. 2007, 129, 2754-2755. [CrossRef]

10. Milios, C.J.; Piligkos, S.; Brechin, E.K. Ground state spin-switching via targeted structural distortion: Twisted single-molecule magnets from derivatised salicylaldoximes. Dalton Trans. 2008, 14, 1809-1817. [CrossRef]

11. Inglis, R.; Milios, C.J.; Jones, L.F.; Piligkos, S.; Brechin, E.K. Twisted molecular magnets. Chem. Commun. 2012, 48, 181-190. [CrossRef] [PubMed]

12. Kalofolias, D.A.; Flamourakis, A.G.; Siczek, M.; Lis, T.; Milios, C.J. A bulky oxime for the synthesis of Mn(III) clusters. J. Coord. Chem. 2015, 68, 1-20. [CrossRef]

13. Tomsa, A.-R.; Martínez-Lillo, J.; Li, Y.; Chamoreau, L.-M.; Boubekeur, K.; Farias, F.; Novak, M.A.; Cremades, E.; Ruiz, E.; Proust, A.; et al. A new family of oxime-based hexanuclear manganese(III) single molecule magnets with high anisotropy energy barriers. Chem. Commun. 2010, 46, 5106-5108. [CrossRef] [PubMed]

14. An, G.-Y.; Cui, A.-L.; Kou, H.-Z. Assembly of oximate-bridged $\mathrm{Mn}_{6}$ cluster to a one-dimensional chain. Inorg. Chem. Commun. 2011, 14, 1475-1478. [CrossRef]

15. Martínez-Lillo, J.; Chamoreau, L.-M.; Proust, A.; Verdaguer, M.; Gouzerh, P. Hexanuclear manganese(III) single-molecule magnets from derivatized salicylamidoximes. C. R. Chim. 2012, 15, 889-894. [CrossRef]

16. Martínez-Lillo, J.; Tomsa, A.-R.; Li, Y.; Chamoreau, L.-M.; Cremades, E.; Ruiz, E.; Barra, A.-L.; Proust, A.; Verdaguer, M.; Gouzerh, P. Synthesis, crystal structure and magnetism of new salicylamidoxime-based hexanuclear manganese(III) single-molecule magnets. Dalton Trans. 2012, 41, 13668-13681. [CrossRef] [PubMed]

17. Martínez-Lillo, J.; Dolan, N.; Brechin, E.K. A cationic and ferromagnetic hexametallic Mn(III) single-molecule magnet based on the salicylamidoxime ligand. Dalton Trans. 2013, 42, 12824-12827. [CrossRef]

18. Martínez-Lillo, J.; Dolan, N.; Brechin, E.K. A family of cationic oxime-based hexametallic manganese(III) single-molecule magnets. Dalton Trans. 2014, 43, 4408-4414. [CrossRef]

19. Martínez-Lillo, J.; Cano, J.; Wernsdorfer, W.; Brechin, E.K. The Effect of Crystal Packing and $\operatorname{Re}^{\mathrm{IV}}$ Ions on the Magnetisation Relaxation of [ $\mathrm{Mn}_{6}$ ]-Based Molecular Magnets. Chem. Eur. J. 2015, 21, 8790-8798. [CrossRef]

20. Rojas-Dotti, C.; Martínez-Lillo, J. Thioester-functionalised and oxime-based hexametallic manganese(III) single-molecule magnets. RSC Adv. 2017, 7, 48841-48847. [CrossRef]

21. Eloy, F.; Lenaers, R. The Chemistry of Amidoximes and Related Compounds. Chem. Rev. 1962, 62, $155-183$. [CrossRef]

22. SHELXTL-2013/4, Bruker Analytical X-ray Instruments; Bruker: Madison, WI, USA, 2013.

23. DIAMOND 4.5.0, Crystal Impact GbR; Crystal Impact: Bonn, Germany, 2018.

(c) 2018 by the authors. Licensee MDPI, Basel, Switzerland. This article is an open access article distributed under the terms and conditions of the Creative Commons Attribution (CC BY) license (http://creativecommons.org/licenses/by/4.0/). 